\title{
Complement C3 Genotype Variants and Risk of Lung Cancer Mortality
}

\author{
Poul Suadicani, ${ }^{1}$ Hans Ole Hein, ${ }^{1,2}$ and Finn Gyntelberg ${ }^{1}$ \\ ${ }^{1}$ The Copenhagen Male Study, Epidemiological Research Unit, Department of Occupational and Environmental Medicine, \\ Bispebjerg University Hospital, Bispebjerg Bakke 23, 2400 Copenhagen NV, Denmark \\ ${ }^{2}$ Research Centre for Prevention and Health, Glostrup University Hospital, 2600 Copenhagen, Denmark
}

Correspondence should be addressed to Poul Suadicani, psua0001@bbh.regionh.dk

Received 3 June 2011; Accepted 7 July 2011

Academic Editor: C. Brambilla

Copyright (C) 2011 Poul Suadicani et al. This is an open access article distributed under the Creative Commons Attribution License, which permits unrestricted use, distribution, and reproduction in any medium, provided the original work is properly cited.

\begin{abstract}
Inflammation and genetic susceptibility influence the risk of lung cancer. During recent years, the role of complement as a part of the humoral response has advanced from being considered complementary to being regarded as a central element in innate immunity. C3 complement allotypes $\mathrm{F}$ and $\mathrm{S}$ have been associated with a number of inflammatory diseases. The C3F allele frequency is approximately $20 \%$ in Caucasian populations and the C3S approximately $80 \%$, resulting in the three predominant genotypes FF (4\%), FS (32\%), and SS (64\%). To our knowledge, no studies have investigated if different C3 allotypes or genotypes predict the risk of lung cancer. We tested in a long-term followup of 3,197 men aged 53 to 74 years the hypothesis that risk of lung cancer would depend on C3 complement genotypes. During 16 years, 160 subjects (5.0\%) died from lung cancer, 68 men (6.1\%) among complement C3 genotypes FS/FF, and 92 men (4.4\%) among genotype SS; age-adjusted hazard ratio with 95\%CI (HR) was 1.42 (1.04-1.94) and strongest, 2.71 (1.34-5.45), among the oldest fifth. C3 complement genotype variants were significantly associated with lung cancer mortality.
\end{abstract}

\section{Introduction}

Inflammation and the nature of the inflammatory response seem to be important determinants in the pathogenesis of lung cancer [1-4]. During recent years, the role of complement as a part of the humoral response has advanced from being considered complementary to being considered a central element in innate immunity. C3 complement is a major player also during the adaptive immune reaction, and the complement system has been suggested to be a potential target for anticancer immunotherapy [5-7]. The C3F allele frequency is approximately $20 \%$ in Caucasian populations and the C3S approximately $80 \%$, resulting in the three predominant genotypes FF (4\%), FS (32\%), and SS (64\%).

Tumor cells in tumor tissues of various origin activate complement components including C3, so complement C3, the most abundant of the complement proteins, may have an important role in the elimination of tumor cells as discussed by Okroj et al. [8] and Jurianz et al. [9]. A number of studies suggest that functional differences exist between C3 complement allotypes $\mathrm{F}$ and $\mathrm{S}$ in the pathogenesis of various diseases like, for example, macula degeneration [10], systemic vasculitis [11], and glomerulonephritis [12] with a higher risk found in individuals with allotype $\mathrm{F}$.

To our knowledge, the association of C3 complement genotypes with lung cancer has not previously been investigated. In order to elucidate the issue, we analysed if C3 complement allo- or genotypes were predictive of lung cancer mortality.

\section{Material and Methods}

2.1. Patient Characteristics. The Copenhagen Male Study (CMS) was set up in 1970-1971 as a prospective cardiovascular cohort study of 5,249 Caucasian men with a mean age of 48 years (range $40-59$ ). The examination comprised a short interview based on a previously completed questionnaire from which information was obtained on lifestyle including smoking habits $[13,14]$. 
In 1985-1986, a new baseline was established giving more comprehensive information about study participants. This baseline was used for the present study. All men from the 1970-1971 study were traced by means of the Danish Central Population Register. Between June, 1985, and June, 1986, all survivors (except 34 emigrants) from the original cohort were invited to take part in this study; 3,387 men (75\%) agreed and gave informed consent; their mean age was 63 years (range 53-74). The 1985-1986 study took place at The Glostrup Population Studies, Glostrup Hospital, University of Copenhagen. Each subject was interviewed about a previously completed questionnaire and subjected to a clinical examination; a venous blood sample was taken for determination of $\mathrm{C} 3$ complement genotypes. With respect to $\mathrm{C} 3$ complement genotypes and lung cancer mortality diagnoses, useful information was available for 3,197 men. For no other single variable included did the proportion of missing values exceed $3 \%$.

\section{Methods}

3.1. Complement C3 Typing. Typing was carried out using agar gel electrophoresis using the method described by Teisberg [15]. Approximately 4\% of C3 tests were discharged because of technical problems in the laboratory. Also 30 men with rare C3 variants were excluded from the analyses. The allotype distribution was in accordance with that of other Caucasian populations [16] resulting in the three predominant genotypes FF (4\%), FS (32\%), and SS (64\%). Due to the small number of men with genotype FF, for the analyses the FF and FS genotypes were pooled.

3.2. Tobacco Smoking Habits. The men classified themselves as never smokers, previous smokers, or current smokers. Current tobacco consumption was calculated from information about the number of cigarettes, cheroots, or cigars or the weight of pipe tobacco smoked daily. 1 cigarette was taken as equivalent to $1 \mathrm{~g}$ tobacco, 1 cheroot as $3 \mathrm{~g}$ tobacco, and 1 cigar as $4 \mathrm{~g}$ tobacco. As previously estimated by means of serum cotinine, the validity of tobacco reporting in the CMS was high [17]. Number of pack years was calculated based on information about average total daily use of tobacco in grams multiplied by number of years as a smoker divided by 20 .

3.3. Dietary Factors. Salt and fat intake was crudely measured based on two simple questions. Do you use more salt in your food than others? Do you try to avoid fat food?

3.4. Alcohol Consumption. Total weekly consumption of alcohol was calculated from questionnaire items about average alcohol consumption on weekdays and at weekends. Intakes of beer, wine, and spirits were reported separately. One drink corresponded to 10-12 g ethanol.

3.5. Occupational Dust Exposure. Information on potentially relevant physical and chemical respirable occupational exposures was obtained from the questionnaire. Long-term exposure was defined as frequent occupational exposure for
TABLe 1: Lifestyle and other characteristics of men with the complement C3 FS/FF compared to men with the complement C3 $\mathrm{SS}$ genotype.

\begin{tabular}{|c|c|c|c|}
\hline & \multicolumn{3}{|c|}{ C3 genotype } \\
\hline & $\mathrm{FS} / \mathrm{FF}$ & SS & $P$ \\
\hline Subjects $n$ & 1122 & 2075 & \\
\hline Age years & $62.7 \pm 5.1$ & $63.1 \pm 5.2$ & 0.05 \\
\hline \multicolumn{4}{|l|}{ Dietary factors } \\
\hline Salt ${ }^{\#}$ & 11.6 & 12.7 & 0.36 \\
\hline Fat ${ }^{\natural}$ & 51.7 & 51.4 & 0.90 \\
\hline \multicolumn{4}{|l|}{ Smoking } \\
\hline Cumulative pack-years & $28.5 \pm 27.2$ & $27.9 \pm 24.5$ & 0.54 \\
\hline Current & 56.0 & 54.1 & 0.31 \\
\hline Cotinine level, & 47.6 & 49.5 & \\
\hline \multicolumn{4}{|l|}{$<100 \mathrm{ng} / \mathrm{mL}$} \\
\hline $100-360 \mathrm{ng} / \mathrm{mL}$ & 25.1 & 25.1 & 0.48 \\
\hline$>360 \mathrm{ng} / \mathrm{mL}$ & 27.3 & 25.4 & \\
\hline Smoking 1970/71 & 68.0 & 68.4 & 0.80 \\
\hline Never & 11.9 & 10.7 & 0.28 \\
\hline \multicolumn{4}{|l|}{ Alcohol use } \\
\hline \multicolumn{4}{|l|}{ Consumption } \\
\hline 0 drinks/week & 12.0 & 10.6 & \\
\hline 1-21 drinks/week & 57.8 & 62.8 & 0.02 \\
\hline$\geq 22$ drinks/week & 30.2 & 26.5 & \\
\hline Beer & 73.7 & 74.3 & 0.75 \\
\hline Wine & 54.9 & 53.4 & 0.42 \\
\hline Spirits intake & 53.7 & 51.3 & 0.20 \\
\hline $\begin{array}{l}\text { Long-term occupational } \\
\text { dust exposure }\end{array}$ & 7.9 & 7.5 & 0.67 \\
\hline
\end{tabular}

Data are presented as mean \pm SD or percentages; ${ }^{\#}$ uses more than others; "does not avoid fatty foods;

$P$-values of unpaired $t$-test or Chi-squared test (likelihood ratio) as appropriate.

at least 5 years. The question was phrased as follows: "Have you at your present or previous work places often, that is several times/week or more, been exposed to dust, asbestos, etc.? If yes, for how many years?"

3.6. End Points. Notification of death and causes of death within the period 1985-1986 to end of 2001 were obtained from the Danish Register of Causes of Death. The ICD lung cancer mortality diagnoses used were codes ICD-8: 162 and, from 1994, ICD-10: C34.

3.7. Statistical Analysis. Basic statistical analyses, including unpaired $t$-test, Chi-square analysis, and regression analyses, were performed. Relative risks were estimated by $\exp (\beta)$, where $\beta$ is the hazard coefficient for the variable of interest in a Cox proportional hazards regression model with the maximum likelihood ratio method adjusting for age [18]. Assumptions for the use of Cox proportional hazards were ascertained by inspection of the log-minus-log function at 
TABLE 2: C3 complement genotypes and risk of lung cancer mortality 1985-1986 to end of 2001 among all men and among the oldest fifth of the cohort $(68$ years + ). Different adjustment criteria are applied in Cox proportional hazards regression analyses with forced entry of variables. Hazard ratios $(95 \% \mathrm{CI})$ are presented.

(a) All men, $n=3,197$

\begin{tabular}{|c|c|c|c|}
\hline & \multicolumn{3}{|c|}{ C3 genotypes } \\
\hline & $\begin{array}{c}\text { SS } \\
n=2075\end{array}$ & $\begin{array}{c}\mathrm{FS} / \mathrm{FF} \\
n=1122\end{array}$ & $P$ \\
\hline Crude incidence, $\%$ & $4.4 \%$ & $6.1 \%$ & \\
\hline \multicolumn{4}{|l|}{ Hazard ratio, adjustment for } \\
\hline (1) Nothing (crude) & $1^{\mathrm{a}}$ & $1.37(1.00-1.87)$ & 0.049 \\
\hline (2) Age & $1^{\mathrm{a}}$ & $1.42(1.04-1.94)$ & 0.029 \\
\hline (3) Age + alcohol intake & $1^{\mathrm{a}}$ & $1.40(1.02-1.91)$ & 0.038 \\
\hline
\end{tabular}

a: Reference

(b) Oldest fifth, $n=606$

\begin{tabular}{lccr}
\hline & \multicolumn{2}{c}{ C3 genotypes } \\
& SS & FS/FF & $n=199$ \\
& $n=407$ & $8.5 \%$ & \\
\hline Crude incidence, $\%$ & $3.7 \%$ & & \\
Hazard ratio, adjustment for & & $2.45(1.22-4.91)$ & 0.01 \\
(1) Nothing (crude) & $1^{\text {a }}$ & $2.71(1.34-5.45)$ & 0.005 \\
(2) Age & $1^{\text {a }}$ & $2.73(1.35-5.51)$ & 0.005 \\
(3) Age + alcohol intake & $1^{\text {a }}$ & & \\
\hline
\end{tabular}

a: Reference

the covariate mean. A two-sided probability value of $P<0.05$ was a priori taken as significant.

3.8. Ethics. Each participant was informed that all personal data were confidential and gave written consent about participation. The study has been approved by the committee for ethics in medical research in the County of Copenhagen.

\section{Results}

Overall, in the population eligible for study, 160 men died from lung cancer (5.0\%) during the period 1985-1986 to end of 2001 .

4.1. Baseline Characteristics. Table 1 shows univariate baseline characteristics of potential risk factors for lung cancer $[19,20]$ according to complement C3 genotype, comparing the FS/FF group with the SS genotype. Differences between the two groups were generally small. The FS/FF group was slightly younger than the SS group, and a statistically significant difference, that is, heterogenous distribution was observed with respect to alcohol use with a slightly higher proportion of abstainers as well as high consumers among the FS/FF genotype. Accordingly, age and alcohol use were regarded as potential confounders and included in the risk analyses presented in Table 2 .

Table 2 shows relative risk (hazard ratio) of lung cancer mortality for the FS/FF genotype compared to genotype SS following different adjustments in forced entry models for the entire cohort (upper part of the table) and for the oldest fifth defined on the basis of quintile of age, 68 years (lower part of the table). The crude incidence of lung cancer mortality was $6.1 \%$ among men with complement C3 genotypes FS/FF (6.7\% among genotype FF, 6.0\% among genotype FS) and $4.4 \%$ among men with C3 SS genotype, a statistically significant difference between the two groups in a Cox proportional hazards analysis adjusting for age. Referencing complement SS genotype, hazard ratio (95\% CI) for genotypes FS/FF was 1.42 (1.04-1.94). Among the oldest fifth, the excess risk of the FS/FF genotype compared to SS was more pronounced with an age-adjusted hazard ratio of 2.71 (1.34-5.45).

In a final analysis, we analysed the hazard ratio of the FS and the FF genotype referencing genotype SS (not shown). The age-adjusted hazard ratio $(95 \% \mathrm{CI})$ for genotype FS was 1.40 (1.01-1.94), $P<0.05$ and for genotype FF 1.57 (0.793.12), $P=0.19$.

\section{Discussion}

Complement C3 genotype variants were associated with risk of lung cancer with a higher risk among men with the $\mathrm{F}$ allotype and significant for men with the FS genotype.

The biological mechanism responsible for this apparent synergy of the $\mathrm{C} 3$ complement genotypes and the $\mathrm{ABO}$ system is at the time speculative. In their recent review paper, Markiewski and Lambris [6] discuss the issue, is complement good or bad for the cancer patients? Our results suggest that genotypes combinations FS and FF are bad and SS is goodat least when it comes to lung cancer and, also, as mentioned 
previously, when it comes to a number of inflammatory diseases [10-12].

\section{Methodological Considerations}

Information on smoking, use of alcohol, and dust exposure in the CMS has previously been found to have a high validity [19]. A few exposure measures are crude, such as the dietary markers of salt intake and fat intake. With respect to the potential risk factors examined, marginal differences were observed between $\mathrm{C} 3$ complement genotypes in the overall distribution of these factors.

\section{Conclusion}

C3 complement genotype variants were significantly associated with lung cancer mortality risk with a higher risk found in men with genotypes FS/FF than SS.

\section{Conflict of Interests}

The authors have no related papers published or submitted for publication, no financial or other conflict of interests, and all authors have read and approved the paper.

\section{Acknowledgment}

This study received grants from The King Christian X's Foundation, The Danish Medical Research Council, The Danish Heart Foundation, and The Else \& Mogens WedellWedellsborg Foundation.

\section{References}

[1] C. M. Ardies, "Inflammation as cause for scar cancers of the lung," Integrative Cancer Therapies, vol. 2, no. 3, pp. 238-246, 2003.

[2] M. Philip, D. A. Rowley, and H. Schreiber, "Inflammation as a tumor promoter in cancer induction," Seminars in Cancer Biology, vol. 14, no. 6, pp. 433-439, 2004.

[3] A. M. Knaapen, P. J. A. Borm, C. Albrecht, and R. P. F. Schins, "Inhaled particles and lung cancer. Part A: mechanisms," International Journal of Cancer, vol. 109, no. 6, pp. 799-809, 2004.

[4] A. Emmendoerffer, M. Hecht, T. Boeker, M. Mueller, and U. Heinrich, "Role of inflammation in chemical-induced lung cancer," Toxicology Letters, vol. 112-113, pp. 185-191, 2000.

[5] M. M. Markiewski and J. D. Lambris, "The role of complement in inflammatory diseases from behind the scenes into the spotlight," American Journal of Pathology, vol. 171, no. 3, pp. 715-727, 2007.

[6] M. M. Markiewski and J. D. Lambris, "Is complement good or bad for cancer patients? A new perspective on an old dilemma," Trends in Immunology, vol. 30, no. 6, pp. 286-292, 2009.

[7] M. M. Markiewski and J. D. Lambris, "Unwelcome complement," Cancer Research, vol. 69, no. 16, pp. 6367-6370, 2009.

[8] M. Okroj, Y. F. Hsu, D. Ajona, R. Pio, and A. M. Blom, "Non-small cell lung cancer cells produce a functional set of complement factor I and its soluble cofactors," Molecular Immunology, vol. 45, no. 1, pp. 169-179, 2008.

[9] K. Jurianz, S. Ziegler, H. Garcia-Schüler et al., "Complement resistance of tumor cells: basal and induced mechanisms," Molecular Immunology, vol. 36, no. 13-14, pp. 929-939, 1999.

[10] J. R. Yates, T. Sepp, B. K. Matharu et al., "Complement C3 variant and the risk of age-related macular degeneration," New England Journal of Medicine, vol. 357, no. 6, pp. 553-561, 2007.

[11] J. E. Finn, L. Zhang, S. Agrawal, D. R. W. Jayne, D. B. G. Oliveira, and P. W. Mathieson, "Molecular analysis of C3 allotypes in patients with systemic vasculitis," Nephrology Dialysis Transplantation, vol. 9, no. 11, pp. 1564-1567, 1994.

[12] J. E. Finn and P. W. Mathieson, "Molecular analysis of C3 allotypes in patients with nephritis factor," Clinical and Experimental Immunology, vol. 91, no. 3, pp. 410-414, 1993.

[13] F. Gyntelberg, "Physical fitness and coronary heart disease in male residents in Copenhagen aged 40-59," Danish Medical Bulletin, vol. 20, no. 1, pp. 1-4, 1973.

[14] F. Gyntelberg, "One and two years incidence of myocardial infarction in Copenhagen males aged 40-59," Danish Medical Bulletin, vol. 22, no. 2, pp. 81-84, 1975.

[15] P. Teisberg, "High voltage agarose gel electrophoresis in the study of C'3 polymorphism," Vox Sanguinis, vol. 19, no. 1, pp. 47-56, 1970.

[16] A. E. Mourant, A. C. Kopec, and K. Damaniewska-Sobcnoak, The Distribution of the Human Blood Groups and Other Polymorphisms, Oxford University Press, London, UK, 1976.

[17] P. Suadicani, H. O. Hein, and F. Gyntelberg, "Serum cotinine validated form of smoking does not account for social inequalities in risk of ischaemic heart disease: the Copenhagen Male Study-4 years' follow-up," International Journal of Epidemiology, vol. 23, pp. 293-300, 1994.

[18] D. R. Cox, "Regression models and life-tables," Journal of the Royal Statistical Society. B, vol. 37, no. 2, pp. 187-220, 1972.

[19] P. Suadicani, H. O. Hein, and F. Gyntelberg, "ABO phenotypes and inflammation-related predictors of lung cancer mortality: the Copenhagen Male Study-a 16-year follow-up," European Respiratory Journal, vol. 30, no. 1, pp. 13-20, 2007.

[20] P. G. Fabricius and P. Lange, "Diet and lung cancer," Ugeskrift for Laeger, vol. 165, no. 34, pp. 3234-3237, 2003 (Danish). 


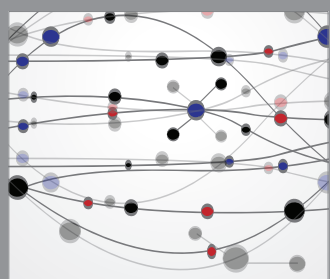

The Scientific World Journal
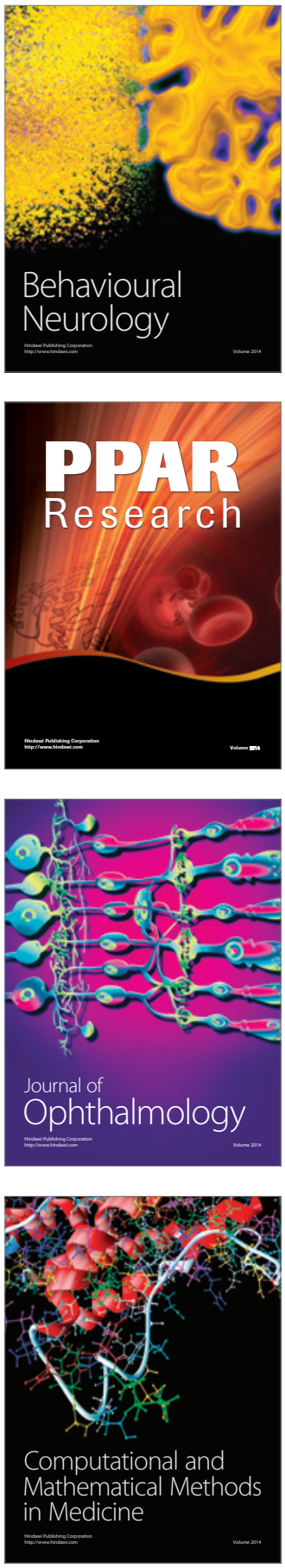

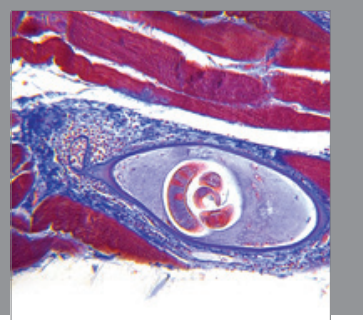

Gastroenterology

Research and Practice
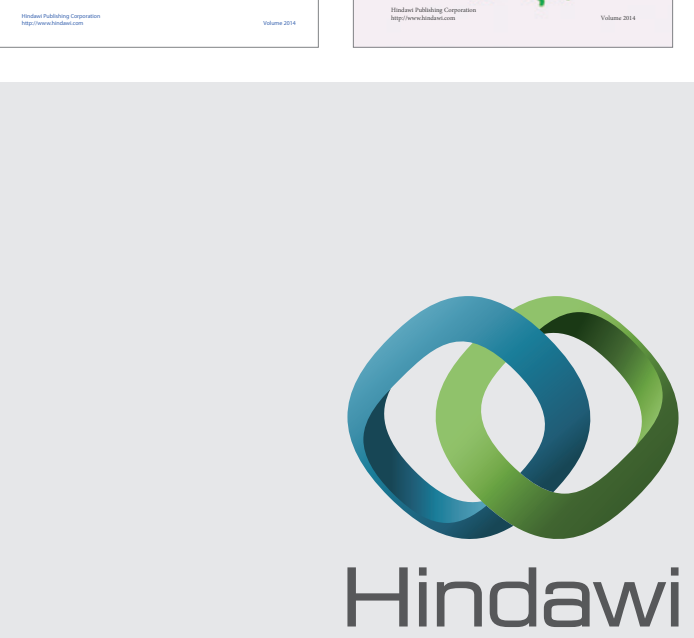

Submit your manuscripts at

http://www.hindawi.com
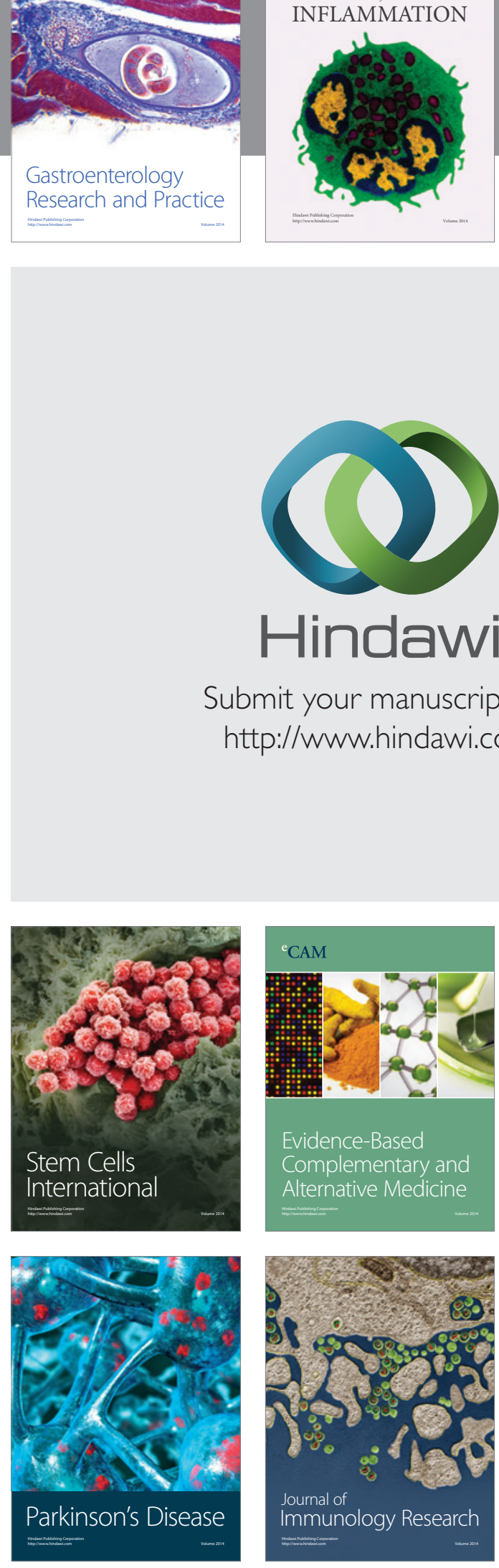

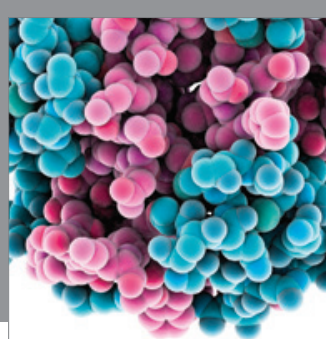

Diabetes Research
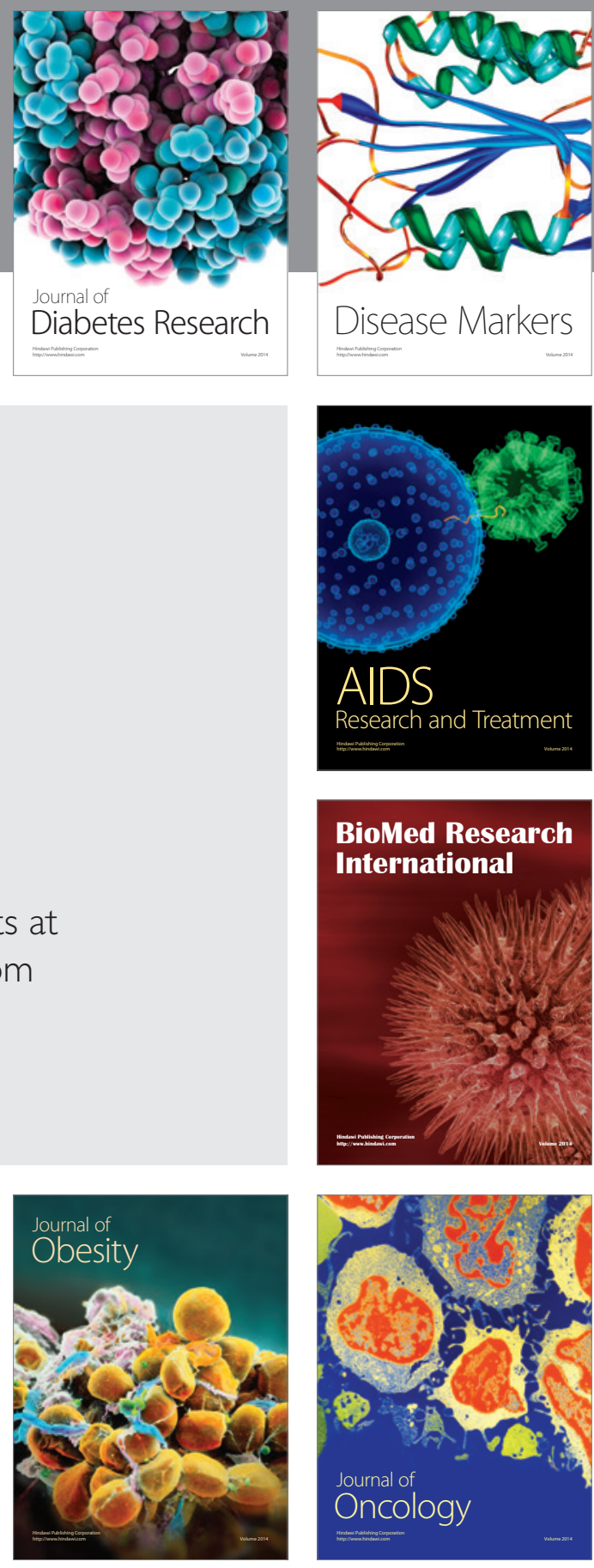

Disease Markers

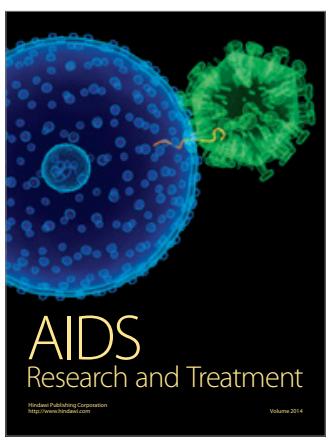

BioMed Research

International
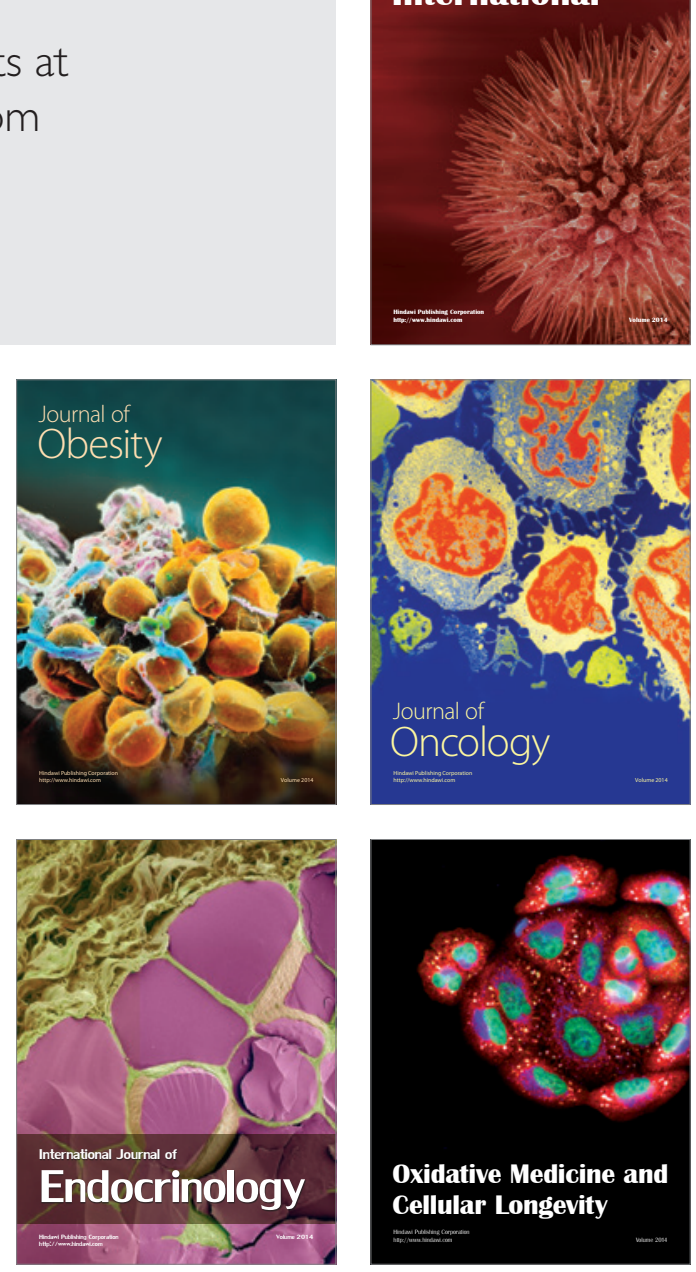